\title{
Nanoindentation analysis of oriented polypropylene: Influence of elastic properties in tension and compression
}

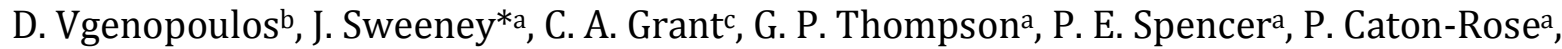 \\ P. D. Coates ${ }^{\mathrm{a}}$
}

aPolymer IRC, Faculty of Engineering \& Informatics, University of Bradford, United Kingdom

bCroda Europe Ltd, Hull, United Kingdom

cHitachi High-Technologies Europe, Warrington, United Kingdom

* Corresponding author. Tel: +44-1274-235456

E-mail address: j.sweeney@bradford.ac.uk (J. Sweeney).

\begin{abstract}
Polypropylene has been oriented by solid-phase deformation processing to draw ratios up to 16 , increasing tensile stiffness along the draw direction by factors up to 12 . Nanoindentation of these materials showed that moduli obtained for indenter tip motion along the drawing direction (3) into to 1-2 plane (axial indentation) were up to $60 \%$ higher than for indenter tip motion along the 2 direction into the 1-3 plane (transverse indentation). In static tests, tensile and compressive determinations of elastic modulus gave results differing by factors up to $\sim 5$ for strain along the draw direction. A material model incorporating both orthotropic elasticity and tension/compression asymmetry was developed for use with Finite Element simulations. Elastic constants for the oriented polypropylene were obtained by combining static testing and published ultrasonic data, and used as input for nanoindentation simulations that were quantitatively successful. The significance of the tension/compression asymmetry was demonstrated by comparing these predictions with those obtained using tensile data only, which gave predictions of indentation modulus higher by up to $70 \%$.
\end{abstract}

Keywords: Polypropylene; Die-drawing; Nanoindentation; Finite elements

\section{Introduction}

Solid-phase orientation is a very effective method of manufacturing polymers with advanced and tailored mechanical properties, especially in the direction of orientation. This improvement is caused by molecular chain alignment arising from deformation as well as strain-induced crystallisation, as has been shown by many investigations over the last four decades (Coates and Ward [1,2]; Richardson et al. [3]; Taraiya et al. [4]; Selwood et al. [5]; 
Morath et al. [6]; Motashar et al. [7]; Ward [8]). Oriented polymers achieve higher stiffness, strength, creep resistance and impact strength compared to the properties of the isotropic polymer (Selwood et al. [9]; Taraiya and Ward [10]; Hansard et al. [11]; Ward et al. [12]; Mohanraj et al. [13]). Mechanical investigation via tensile and impact testing are the customary methods for quantifying the improvement in properties.

Nanoindentation is now well established as a means of measuring hardness and elastic properties for a range of polymers (Briscoe et al. [14]; Jee and Lee [15]; Gibson [16]). Some studies have focussed on polypropylene (Chen et al.[17]; Lesan-Khosh et al. [18]; Zia et al. [19]). To investigate elastic properties, the unloading behaviour is analysed so that only recovery and therefore elastic behaviour is observed. Tests then yield an elastic parameter that is in general known as the indentation modulus. In the case of isotropic material, the indentation modulus is identified with the plane strain or reduced modulus, which is simply related to Young's modulus and Poisson's ratio $[14,18]$. When the material's elastic behaviour is anisotropic, the same measurement may be performed, but its interpretation in terms of elastic parameters is more complex; this is inevitable as there is then no unique plane strain modulus. Despite this, a number of workers have derived indentation moduli on anisotropic material and referred to them as reduced moduli. Thus, Beake and Leggett [20] have reported reduced modulus values obtained by indenting biaxially drawn, and therefore anisotropic, PET film. Similarly, Fasce et al. [21] have reported reduced moduli obtained by nanoindentation of polypropylene films, for which they also report tensile moduli which differ for machine and transverse directions. Norambuena-Contreras et al [22] also used the isotropic analysis when analysing a series of polymer fibres, which clearly displayed some anisotropy. In the work reported here, we shall bring clarity to the nanoindentation of oriented polymer by adopting an anisotropic elastic approach that expresses indentation modulus in terms of the appropriate elastic constants.

In addition to elastic anisotropy, oriented polymer also exhibits tension-compression asymmetry (Senden et al. [23]; Duckett et al. [24]). Nanoindentation introduces a complex stress field that includes both tensile and compressive regions. The elastic analysis applied here will include this effect and use both tensile and compressive experimental stress-strain data to parameterize it.

In the present work, we have produced strips of uniaxially oriented polypropylene by diedrawing to draw ratios up to 15.9. We then performed nanoindentation experiments on both the isotropic and the oriented materials by indenting in all 3 axes; both along the direction of drawing and the two axes transverse to it, providing values for the elastic indentation modulus that are seen to be higher by up to $60 \%$ for axial tests in comparison with transverse measurements. To understand these results in terms of macroscopic elastic properties, we have found it essential that, for measurement along the draw direction, the large differences in elasticity between tensile and compressive tests be taken into account. In addition, the orthotropic nature of the elasticity must be included in any analysis. Elastic properties are generated by tensile, bend and compression testing in combination with published ultrasonic measurements that provide Poisson's ratio and shear modulus data. The Poisson's ratio values are used directly, whereas the ultrasonic shear moduli provide a ratio that is assumed to be the same as for the static shear moduli; details are given in Section 4.3 below. 
The elastic properties are used to parameterise an orthotropic elastic material model, which distinguishes between states of tension and compression along the material draw direction. This model is incorporated into Finite Element simulations of the nanoindentation for both axial and transverse tests and gives generally successful predictions of indentation modulus. In contrast, simulations for which tensile and compressive behaviour is assumed to be the same and defined by tensile measurements, give predictions of indentation modulus that are high by up to $70 \%$. These findings have implications for all oriented polymers, and also potentially for all materials, including biological systems, for instance cortical bone, that derive their anisotropy from oriented molecules or fibrils, and so can show asymmetry with respect to tension and compression (Carnelli et al. [25]; Reisinger et al. [26]; Casanova [27]).

\section{Materials and methods}

\subsection{Material}

The particular polypropylene (PP) grade chosen for this study was an isotactic homopolymer with a melt flow index of $3 \mathrm{gr} / 10 \mathrm{~min}$, a melting point of $165^{\circ} \mathrm{C}$ and molecular mass of $M_{\mathrm{w}}=$ $405,000\left(M_{\mathrm{n}}=55,100\right)$, as given by the material manufacturers (Sinopec plc). The crystallinity of the as-received granules was measured to be $44.3 \%$ by Differential Scanning Calorimetry (TA Instruments Q20).

Sheets of approximately $9 \mathrm{~mm}$ in thickness were produced by compression moulding the PP granules at $210^{\circ} \mathrm{C}$, and then rapidly cooled at approximately $40^{\circ} \mathrm{C} / \mathrm{min}$. Rectangular strips cut from the sheet, approximately $20 \mathrm{~mm}$ wide and $150 \mathrm{~mm}$ long, form the starting billets for the uniaxial die-drawing experiments.

\subsection{Uniaxial die-drawing}

The solid-phase die-drawing technique, in which polymer is pulled through a converging die, has been described extensively in past studies $[1,2,8]$ and is depicted in Fig. 1 . The polymer is die-drawn at an elevated temperature that is above its glass transition temperature, and below its melting temperature. An increase in axial extension ratio is induced in the polymer as it moves through the die-section, and also beyond the die-exit by "free-drawing". We define the true draw ratio as:

$$
\lambda_{\mathrm{A}}=\frac{A_{0}}{A_{\mathrm{f}}},
$$

where $A_{0}$ is the initial cross-sectional area of the billet and $A_{\mathrm{f}}$ the cross-sectional area of the final product, which can readily be evaluated from the initial and final dimensions [3] $\lambda_{\mathrm{A}}$ is equal to the conventional axial extension ratio if there is no change in volume. It is convenient to also define the nominal draw ratio as:

$$
\lambda_{\mathrm{N}}=\frac{A_{0}}{A_{\text {die }}}
$$


where $A_{\text {die }}$ is the cross-sectional area of the die exit $\left(A_{\text {die }}=w_{0} t_{\text {die }}\right.$, with $w_{0}$ initial billet-width and $t_{\text {die }}$ die exit gap).

The die-drawing apparatus used in these experiments consists of a heating chamber and a converging die, of $30^{\circ}$ full-angle, mounted on a tensile testing machine (Messphysik ME588). The die-exit gap is adjustable by inserting various thicknesses of shims between the two halves of the split die, allowing $\lambda_{\mathrm{N}}$ to be set. For each die-drawing experiment, a polymer billet is placed in the heating chamber with a small "tag" protruding from the die-exit, gripped by the upper-clamp of the tensile testing machine. The billet is allowed to reach thermal equilibrium at the required temperature of $150^{\circ} \mathrm{C}\left(15^{\circ} \mathrm{C}\right.$ below the melt) before the testing machine is activated to pull the polymer through the die. It is necessary to start the process off at slow speed with the die not fully tightened, and gradually increasing the applied draw up to the required values of $\lambda_{\mathrm{N}}$ and drawing speed $v$; the converging profile within the die is thus established without initially machining it into shape.

In this work, we compared unoriented compression-moulded PP (for which $\lambda_{\mathrm{N}}=1$ ) with the following three cases of PP uniaxially die-drawn at $150^{\circ} \mathrm{C}$ with increasing levels of induced orientation: $\lambda_{\mathrm{N}}=2$ at $v=31 \mathrm{~mm} / \mathrm{min}, \lambda_{\mathrm{N}}=4$ at $v=250 \mathrm{~mm} / \mathrm{min}$, and $\lambda_{\mathrm{N}}=6.7$ at $v=1000$ $\mathrm{mm} / \mathrm{min}$.

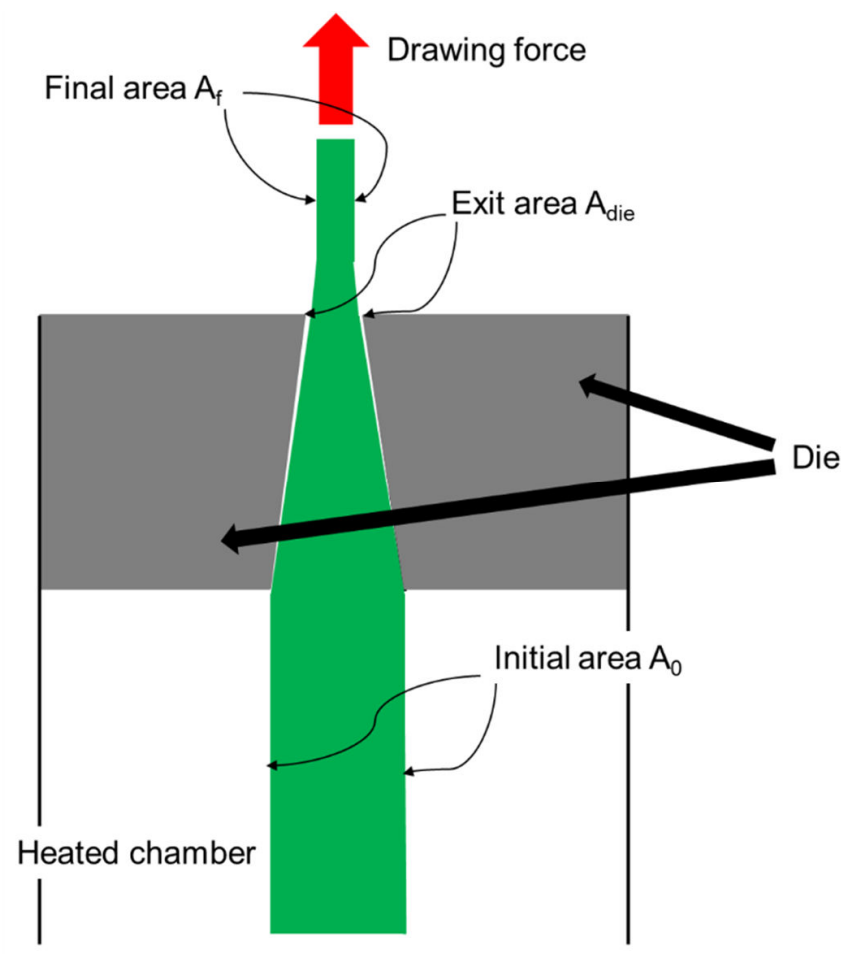

Fig. 1. Schematic of the die-drawing process. A billet of polymer in the solid phase is pulled through a converging die, reducing the cross-sectional area. Further "free-drawing" occurs beyond the die (sometimes the polymer pulls away from the die walls as shown). The polymer cools as it moves beyond the die, eventually reaching a constant cross-section. 


\subsection{Density measurements}

The density of all samples was obtained using a multivolume pycnometer 1305 by Micromeritics. The apparatus uses Helium to measure the volume difference between the reference and test samples to produce the density measurement.

\subsection{Differential Scanning Calorimetry (DSC)}

DSC tests were conducted in a Q20 apparatus by TA Instruments, primarily to measure crystallinity. The selected test type was a heat/cool/heat starting at $30^{\circ} \mathrm{C}$ and finishing at $210^{\circ} \mathrm{C}$ at a $5^{\circ} \mathrm{C} / \mathrm{min}$ heating and cooling rate.

\subsection{Surface topography}

The surfaces to be nanoindented were characterised using an Olympus LEXT OLS4000 3D measuring laser microscope. This instrument produced values of surface parameters such as roughness $R_{a}$ averaged over approximately square regions of area $\sim 0.01 \mathrm{~mm}^{2}$.

\subsection{Nanoindentation}

The die-drawn polymer was sufficiently thick (in the range $0.73 \mathrm{~mm}$ to $4 \mathrm{~mm}$ ) to allow nanoindentation tests (denoted axial tests) to be conducted with indenter tip motion along the axis of drawing (the 3 axis) into a surface in the 1-2 plane (see Fig.2). Other (transverse) nanoindentation tests were conducted with indenter tip motion along the 1 axis into the 2-3 plane, or with indenter tip motion along the 2 axis into the 1-3 plane (see Fig. 2). This work presents for the first time nanoindentation testing of oriented polymer along all three directions, along the orientation axis as well as the two transverse ones.

Surface topography can influence nanoindentation results. Qasmi and Delobelle [28], operating on a range of materials using a Berkovich indenter, showed experimentally that, for both elastic modulus and hardness derived from nanoindentation, the standard deviations were directly dependent on the ratio $R_{\mathrm{RMS}} / h_{c \max }$, where $R_{\mathrm{RMS}}$ is the root-meansquare roughness and $h_{c \max }$ is the maximum penetration depth; thus, the increase in standard deviation arising from the surface is small when this ratio is small. Similarly, modelling work on rubberlike materials tested with a spherical indenter (Chen and Diebels [29]) has shown that roughness effects are negligible when $\left(H / h_{c \max }\right)<0.1$, where $H$ is the surface asperity height.

The transverse indentations were performed on the as-processed polymer surfaces with no additional surface preparation. These surfaces take their roughnesses largely from the metal surfaces they contact during processing, and, averaged over all draw ratios, were characterised by $R_{a}=0.54 \mu \mathrm{m}$ and $R_{R M S}=0.71 \mu \mathrm{m}$. For axial indentation, the surfaces were created by sawing and then smoothing the sawn surface by microtoming at room temperature (Leica RM2265 Rotary microtome). These surfaces were characterised by $R_{a}=$ $1.28 \mu \mathrm{m}$ and $R_{\mathrm{RMS}}=1.71 \mu \mathrm{m}$. These figures are to be compared with the experimental value of $h_{c \max }$ of $7 \mu \mathrm{m}$. Qasmi and Delobelle [28] derived an empirical formula for the relative standard deviation (RSD) in modulus attributable to surface roughness, as: 


$$
\mathrm{RSD}=0.346\left(\frac{\mathrm{R}_{\mathrm{RMS}}}{\mathrm{h}_{\mathrm{c} \text { max }}}\right)^{0.66}
$$

This enables an estimate of RSD of 7\% for transverse tests and 13\% for axial tests. The RSDs observed for the measurements in Fig. 10 below are in the range 4-8\% for all tests. These estimates are consistent with some contribution of the surface roughness to the error, which is itself within reasonable bounds.

Static indentation tests were conducted, at room temperature, on a Nanoindenter Hysitron TI 950 (Hysitron, Minneapolis, USA), using a three-sided pyramidal Berkovich diamond indenter. Fig. 2 (a) shows the material coordinate system used here for the die-drawn polymer billet. Square samples of $10 \mathrm{~mm}$ by $10 \mathrm{~mm}$ were cut from the die-drawn product (or the undeformed billet) and mounted in the indenter in such a way as to allow axial or transverse indentation. For both the axial tests and the transverse tests into the 2-3 plane, separate indents were executed in a $3 \times 100$ square-grid pattern placed on the 1-2 and the 23 face of the sample, respectively; and for the transverse tests into the 1-3 plane, a 30x30 grid was used. The separation between adjacent indents was $0.1 \mathrm{~mm}$. Each indent was performed to a peak load of $100 \mathrm{mN}$ with a loading/unloading rate of $20 \mathrm{mN} / \mathrm{sec}$ and a holding time (at peak load) of $15 \mathrm{~s}$. For transverse tests, indentation is always into an anisotropic plane, so there is a possibility that the orientation of the indenter with respect to the molecular orientation (3) axis could affect the results. A standard procedure was adopted so that one of the sides of the indenter's triangular cross-section was parallel to the 3 direction (see Fig. 2(b)). The significance of the indenter orientation is explored by modelling below in section 4.6 .

Following the Oliver-Pharr method (Oliver and Pharr [30]), the nanoindentation results are given in terms of the indentation modulus:

$$
M=\frac{s}{2} \sqrt{\frac{\pi}{A}},
$$

where the stiffness $s$ is given by the slope of the unloading curve $s=\mathrm{d} P / \mathrm{d} h$, with P the applied load and $h_{\mathrm{c}}$ the indentation depth, and $A=A\left(h_{\mathrm{c}}\right)$ is the projected contact area as a function $h_{\mathrm{c}}$. A calibration procedure was initially performed (to obtain the area of contact $A$ at different values of $h_{\mathrm{c}}$ ) using a reference sample of polycarbonate with known stiffness $s$ provided by the manufacturers. We denote the indentation modulus as $M_{3}$ for axial tests, and $M_{1}$ and $M_{2}$ for transverse tests, where the 1 and 2 indices correspond to the direction of motion of the indenter tip. 


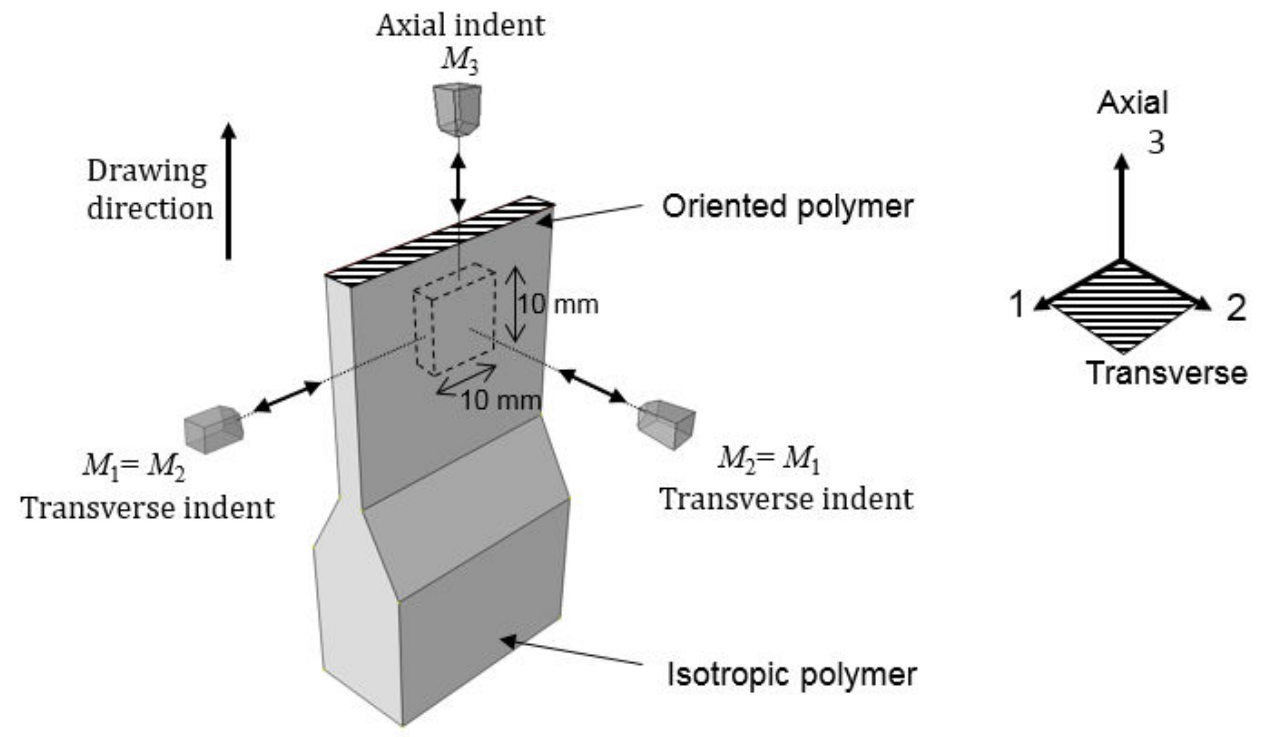

(a)

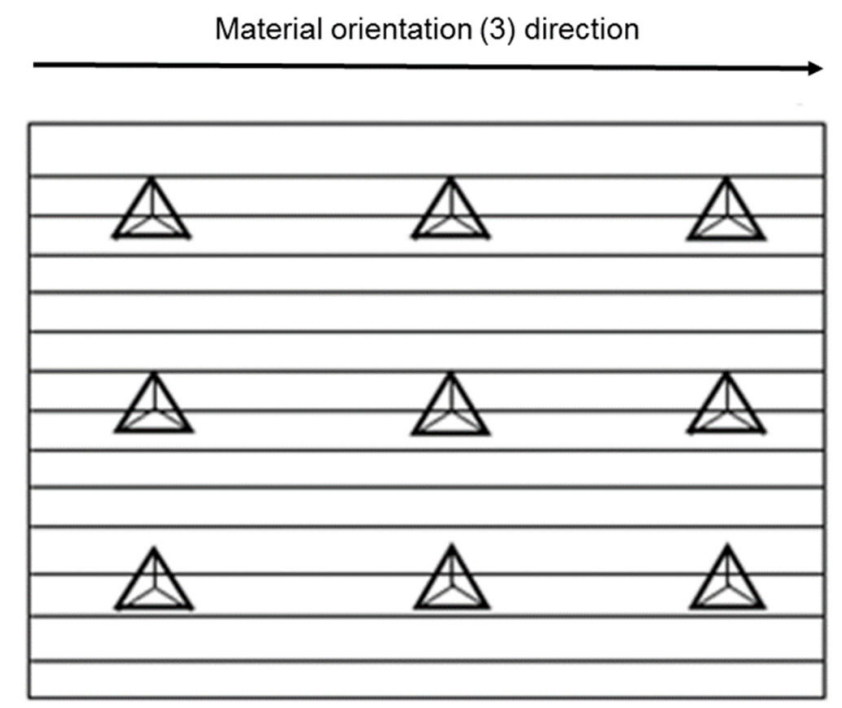

(b)

Fig. 2 (a) Die-drawn material coordinate system. The polymer is drawn and oriented along the axial direction (3), producing a transversely isotropic material, with isotropy in the 1-2 plane (cross-hatched). Nanoindentation tests were performed on samples cut through the thickness as indicated (dotted lines), with the indenter tip moving in the axial $(3)$ and transverse $(1,2)$ directions. (b) Configuration of indenter tip for transverse tests. 


\subsection{Elastic properties}

The tensile behaviour was determined via tensile testing at room temperature. Flat dog-bone tensile specimens with a gauge length of $12 \mathrm{~mm}$ were cut through the die-drawn product (with the axis along the drawing direction), or the initial compression moulded sheet, using an ISO 527-2:1996 5B type cutter. Tests were conducted on a Messphysik ME2-233 testing machine using a constant cross-head speed of $7.5 \mathrm{~mm} / \mathrm{min}$ (nominal strain rate of $0.01 \mathrm{~s}^{-1}$ ). A video-extensometer system (Messphysik ME46-NG) was used to accurately measure strain by tracking the distance between several targets marked along the gauge length of the sample. Engineering stress was determined from the measured force and the initial crosssectional area, and true stresses $\sigma$ were calculated from engineering stresses on the assumption of incompressibility, i.e. $\sigma=\lambda \sigma_{E}$, where $\sigma_{E}$ is the engineering stress and $\lambda$ the extension ratio imposed by the testing machine. From each tensile test, we also determined the true yield stress, true tensile strength and strain at break.

Compressive behaviour was also of interest as it is of direct relevance to the interpretation of nanoindentation. For testing of oriented polymers along the direction of orientation, it has been observed that Young's modulus is significantly greater in tension than in compression, even at the relatively low levels of orientation induced in melt processing [23]. Yield stress is also highly asymmetrical with respect to tension and compression [24]. Direct compressive measurements on the die-drawn strips were not generally possible because of their thinness $(0.73 \mathrm{~mm}$ for the highest draw ratio). To circumvent this problem, two strategies were adopted: die-drawn material in the form of rod was used for direct axial compression measurements; and three-point bend tests were performed on the die-drawn strips and the values of compressive moduli deduced, using the data for tensile moduli generated by the tensile testing described above.

Compression testing was performed on die-drawn cylindrical specimens having diameters in the range 3.2 to $3.8 \mathrm{~mm}$ and $10 \mathrm{~mm}$ in height, with end-faces machined flat and parallel. Extruded cylindrical billets of diameter $12.3 \mathrm{~mm}$ were die-drawn at $150{ }^{\circ} \mathrm{C}$ through conical dies, of full-angle $30^{\circ}$ and die-exit diameter $d$, to give two levels of orientation $(d=6.0 \mathrm{~mm}$ at $v=3000 \mathrm{~mm} / \mathrm{min}$ to produce the lowest orientation with $\lambda_{\mathrm{N}}=4.2$, and $d=4.7 \mathrm{~mm}$ at $v=500$ $\mathrm{mm} / \mathrm{min}$ for a higher orientation with $\lambda_{\mathrm{N}}=6.8$ ). The specimens were compressed between flat steel platens using an Instron 5568 testing machine at a cross-head speed of $1 \mathrm{~mm} / \mathrm{min}$ (nominal strain rate of $0.016 \mathrm{~s}^{-1}$ ). A universal joint was included in the loading system to eliminate any non-parallelism of the platens. Strains were again measured using video extensometry as described above.

Bend tests were conducted on rectangular strips and die-drawn product, so that samples had thicknesses that varied considerably $(4.0,1.9$ and $0.73 \mathrm{~mm}$ for draw ratios of $2.8,6.5$ and 15.9 respectively). Experiments were performed in three-point bend using an Instron 5568 testing machine. Widths were in the range $4-18 \mathrm{~mm}$ and spans $30-80 \mathrm{~mm}$, and testing speeds were such as to produce strain rates comparable with the $0.01 \mathrm{~s}^{-1}$ value used in the tensile experiments. Both isotropic and anisotropic samples were tested using the ASTM D790M-93 test method. The test specimens used were approximately $21 \mathrm{~mm}$ in width and $8.5 \mathrm{~mm}$ in thickness. A span length of $136 \mathrm{~mm}$ was chosen, which corresponded to a support span to thickness ratio equal to 16 , as proposed by the test standard. A test speed of 
$222 \mathrm{~mm} / \mathrm{min}$ was used in order to maintain the same strain rate of $0.01 \mathrm{~s}^{-1}$ as used in all mechanical tests.

\subsection{Finite element modelling}

The finite element method has been used on numerous occasions for the analysis of indentation (for example: Bhattacharya and Nix [31]; Lichinchi et al. [32]; Dao et al. [33]; Huang and Pelegri [34]; Sakharova et al. [35]2009). Three-dimensional analyses of isotropic material have been used to investigate the effect of indenter shape [35, 36].

In nanoindentation, materials are generally recognised as behaving in an elastic-plastic manner, and the elastic behaviour is derived experimentally via the force-displacement curve in unloading. During unloading, stresses decrease and no further yielding is induced, so the drop in force is associated purely with elastic behaviour. In analysing indentation for the purpose of deriving elastic parameters, the complications of plasticity are avoided by assuming that the behaviour is purely elastic, so that the loading and unloading curves should ideally be identical, and the calculated slopes s in equation (4) are taken from the combined loading-unloading curves. Fig. 3 shows a model in the commercial code ABAQUS [36](ABAQUS 2016) in which a rectangular solid of orthotropic elastic material is penetrated at its centre by a rigid surface with the geometry of a Berkovich indenter. Eight-noded linear hexahedral elements are used, with ABAQUS/STANDARD (static) analysis and nonlinear geometry. 


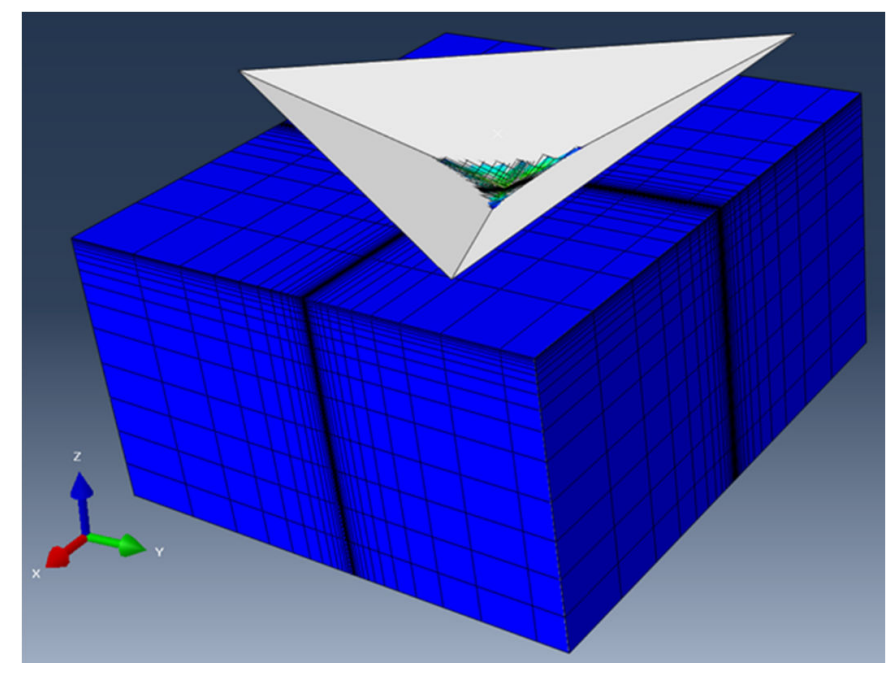

(a)

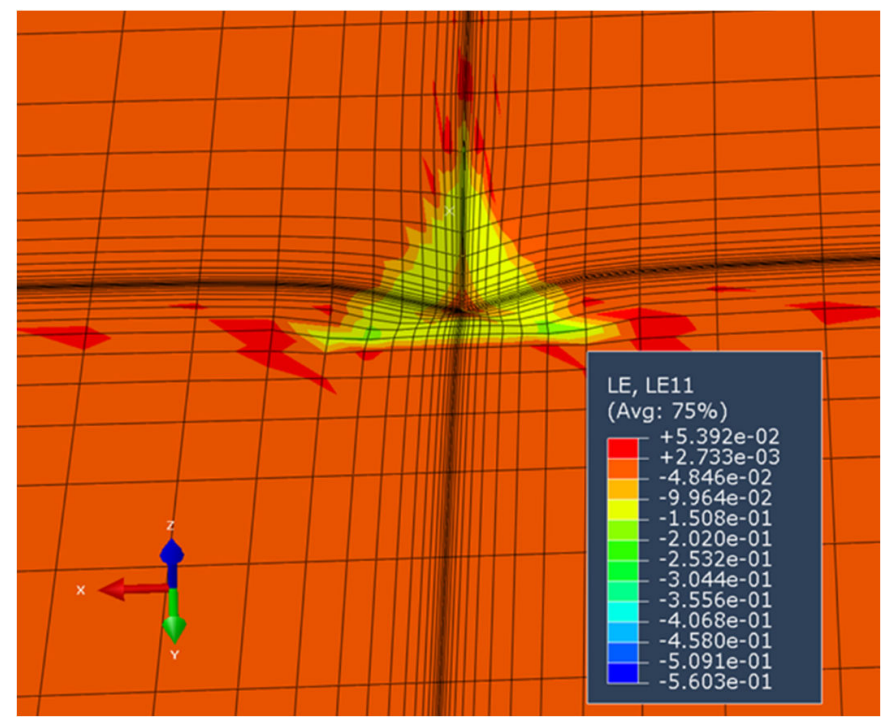

(b)

Fig. 3. Finite element model of indentation. For axial tests the 3 material direction (orientation direction) is along the $\mathrm{z}$-axis. For transverse tests the orientation direction is along the $\mathrm{x}$-axis, so that the indenter is oriented as in the experiments. (a) General view, with indenter inserted. (b) The indented area with indenter removed from the image, showing predominantly compressive strain along z-axis below the indenter.

The vertical boundaries are free and deform negligibly, showing that the model is equivalent to a solid of infinite extent in the xy plane. The bottom surface is fixed in all three directions. The rigid surface is subject to a displacement boundary condition that moves it along the zdirection to indent and then withdraw from the top surface of the solid. The total vertical 
load on the rigid surface and its position are output, as is the contact area of the interface between the indenter and the elastic solid, at each time increment. The contact area $A_{\mathrm{c}}$ is available from ABAQUS as the output variable CAREA. Values of indentation modulus $M_{1}$ or $M_{3}$ are derived from the force-displacement curve using equation (4), with the projected area $A$ calculated from the contact area $A_{\mathrm{c}}=$ CAREA by:

$$
A=A_{c} \sin \alpha,
$$

where $\alpha$ is the angle that the face of the Berkovich indenter makes with its central axis $(\alpha=$ $65.27^{\circ}$, see Fig. 4). Equation (5) is also valid for a conical indenter, when $\alpha$ is the cone semiangle. The gradient $s$ in equation (4) is calculated at each time increment by numerically differentiating the in total load-displacement relation. The $(x, y, z)$ axes as shown in Fig. 3 are fixed in space. For transverse indentation along the material 2 axis the $\mathrm{x}, \mathrm{y}$ and $\mathrm{z}$ spatial directions correspond respectively to the 1, 3 and 2 material axes (Fig. 2Error! Reference source not found.). For axial indentation along the draw direction, the $\mathrm{x}, \mathrm{y}$ and $\mathrm{z}$ spatial directions correspond respectively to the 1, 2 and 3 material axes. Elastic material data in the form of compliance constants (Table 3) are used in the models. The material model used was asymmetrical in tension and compression (see section 3.3 below). It was programmed as a UMAT subroutine in ABAQUS, and parameterised by compliance constants determined from experimental data (see section 4.3 below).

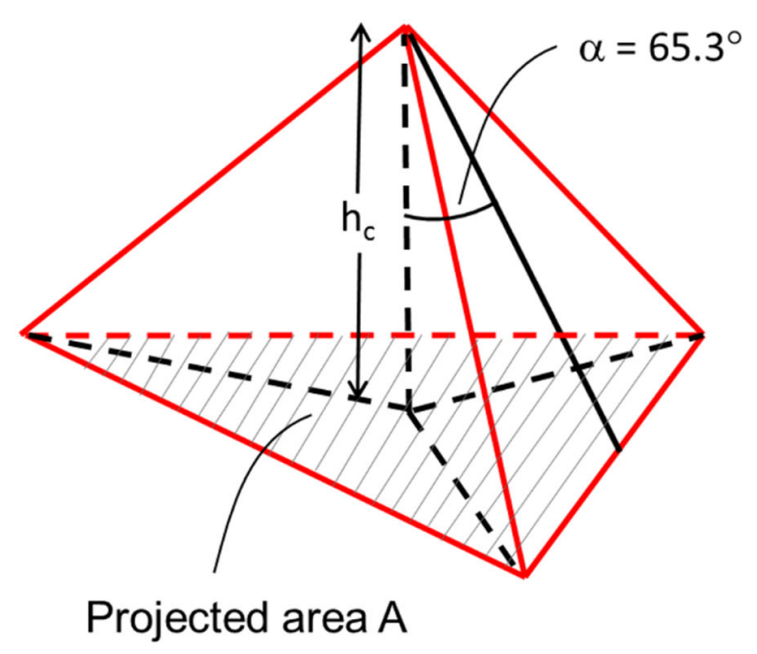

Fig. 4. Berkovich indenter. The shaded area is the projected area $A$, the unshaded triangular faces form the contact area $A_{\mathrm{c}}$ and $h_{\mathrm{c}}$ is the penetration depth. Maximum value of $h_{\mathrm{c}}$ is $\sim 7 \mu \mathrm{m}$.

\section{Nanoindentation analysis}

In this section, the theory required to relate the elastic measurements to the nanoindentation results is outlined. 


\subsection{Elastic constants}

For the analysis, mechanical data are available as moduli along the draw (3) direction $E_{\mathrm{t}}$ and $E_{\mathrm{c}}$ (Table 2). It was assumed that the drawing is uniaxial, so that $E_{1}=E_{2}$ (see Fig. 2Error! Reference source not found.). With this degree of symmetry (i.e. transversely isotropic in the 1-2 plane), a total of six elastic constants are required and Hooke's law can take the form [38]:

$$
\left(\begin{array}{l}
\varepsilon_{11} \\
\varepsilon_{22} \\
\varepsilon_{33} \\
\varepsilon_{13} \\
\varepsilon_{23} \\
\varepsilon_{12}
\end{array}\right)=\left(\begin{array}{cccccc}
s_{11} & s_{12} & s_{13} & 0 & 0 & 0 \\
s_{12} & s_{11} & s_{13} & 0 & 0 & 0 \\
s_{13} & s_{13} & s_{33} & 0 & 0 & 0 \\
0 & 0 & 0 & s_{44} & 0 & 0 \\
0 & 0 & 0 & 0 & s_{44} & 0 \\
0 & 0 & 0 & 0 & 0 & s_{66}
\end{array}\right)\left(\begin{array}{l}
\sigma_{11} \\
\sigma_{22} \\
\sigma_{33} \\
\sigma_{13} \\
\sigma_{23} \\
\sigma_{12}
\end{array}\right) .
$$

The $\sigma_{i j}$ are the stress components, $\varepsilon_{i j}$ the strains and the $s_{i j}$ are components of the compliance matrix $\mathbf{S}$. Here the 3 axis is a symmetry axis and corresponds to the draw direction. For Young's modulus $E_{1}$ along the 1 and 2 axes, and $E_{3}$ along the 3 -axis, we have:

$$
\begin{gathered}
s_{11}=\frac{1}{E_{1}} \\
s_{33}=\frac{1}{E_{3}}
\end{gathered}
$$

The off-diagonal terms in $\mathbf{S}$ relate to Poisson's ratios $v_{21}, v_{31}$ and $v_{13}$ as:

$$
\begin{aligned}
& S_{12}=-v_{21} S_{11} \\
& S_{13}=-v_{31} S_{11}, \\
& S_{13}=-v_{13} S_{33}
\end{aligned}
$$

and the remaining diagonal terms:

$$
\begin{aligned}
& s_{44}=\frac{1}{2 G_{44}} \\
& s_{66}=\frac{1}{2 G_{66}}
\end{aligned}
$$

are simply related to shear moduli for $G_{44}$ and $G_{66}$ at the 1-3 and 1-2 planes respectively. For the form of symmetry given here isotropy of the 1-2 plane results in:

$$
s_{66}=2\left(s_{11}-s_{12}\right),
$$

and thus there are a total of five independent elastic constants $s_{i j}$. 
For the same uniaxial symmetry, Hooke's law can also be expressed in a form that gives the stress in terms of the strain as:

$$
\left(\begin{array}{l}
\sigma_{11} \\
\sigma_{22} \\
\sigma_{33} \\
\sigma_{13} \\
\sigma_{23} \\
\sigma_{12}
\end{array}\right)=\left(\begin{array}{cccccc}
C_{11} & C_{12} & C_{13} & 0 & 0 & 0 \\
C_{12} & C_{11} & C_{13} & 0 & 0 & 0 \\
C_{13} & C_{13} & C_{33} & 0 & 0 & 0 \\
0 & 0 & 0 & C_{44} & 0 & 0 \\
0 & 0 & 0 & 0 & C_{44} & 0 \\
0 & 0 & 0 & 0 & 0 & C_{66}
\end{array}\right)\left(\begin{array}{l}
\varepsilon_{11} \\
\varepsilon_{22} \\
\varepsilon_{33} \\
\varepsilon_{13} \\
\varepsilon_{23} \\
\varepsilon_{12}
\end{array}\right),
$$

where the $C_{i j}$ are the stiffness constants and the square matrix $\mathbf{C}$ is the stiffness matrix. Once $\mathbf{S}$ is known, $\mathbf{C}$ can be determined as it is the inverse of $\mathbf{S}$,

$$
\mathbf{C}=\mathbf{S}^{-1} \text {. }
$$

\subsection{Indentation modulus}

The indentation modulus $M$ is calculated using equation(4), and depends only on the stiffness $s$, given by the measured unloading slope, and the projected area $A$, given by the measured indentation depth. All the analysis of indentation available in the literature so far has used conventional elasticity theory in which elastic constants are assumed to be the same in tension and compression. We know this to be untrue for oriented polymer and we shall develop a numerical method below for analysis of the experimental results. However, the conventional results presented here are useful for comparison and verification purposes. They are arrived at by assuming axisymmetric conditions (i.e. a conical indenter). Simplifying further and assuming isotropic material, it is found that $M$ is equal to the plane strain or reduced modulus $E_{\mathrm{r}}$ defined by:

$$
E_{\mathrm{r}}=\frac{E}{1-v^{2}},
$$

where $E$ is Young's modulus and $v$ Poisson's ratio. For anisotropic materials, however, $M$ is a more general concept and is a function of the various elastic constants. For instance, Delafargue and Ulm [39] have produced expressions for indentation modulus of orthotropic materials along principal material axes in the case of a conical indenter. For transverse material isotropy, where the 3 -axis is the axis of material symmetry, the indentation modulus for indentation along the 3 -axis is derived analytically by Delafargue and Ulm as:

$$
M_{3}^{\mathrm{a}}=2 \sqrt{\frac{C_{11} C_{33}-C_{13}^{2}}{C_{11}}\left(\frac{1}{C_{44}}+\frac{2}{\sqrt{C_{11} C_{33}}+C_{13}}\right)^{-1}} .
$$

For indention normal to the draw direction analytic the indentation modulus is given by: 


$$
M_{1}^{\mathrm{a}}=\sqrt{\frac{C_{11}^{2}-C_{12}^{2}}{C_{11}} \sqrt{\frac{C_{11}}{C_{33}}} M_{3}^{\mathrm{a}}}
$$

Equations (14) and (15) provide indentation modulus values for materials that are linear elastic and symmetrical in response to tension and compression when a conical indenter is used. They will be used to verify the numerical method described in section 2.8.

\subsection{Asymmetry in tension-compression}

Our model of oriented polymer recognises the asymmetry in elastic modulus when loading in tension or compression along the draw direction. Since a hydrostatic pressure does not generally induce yielding or structural changes, it is assumed, as with plasticity theory that the deviatoric stress controls whether the response corresponds to tension or compression. With molecular orientation along the 3-direction, the material law takes the form of equation (6), with:

$$
\begin{aligned}
& \sigma_{33}-\bar{\sigma} \geq 0: \mathbf{S}=\mathbf{S}^{\mathbf{t}} \\
& \sigma_{33}-\bar{\sigma}<0: \mathbf{S}=\mathbf{S}^{\mathbf{c}}
\end{aligned}
$$

where

$$
\bar{\sigma}=\frac{\sigma_{11}+\sigma_{22}+\sigma_{33}}{3}
$$

is the hydrostatic stress, $\mathbf{S}$ is the compliance matrix of equation (6) and $\mathbf{S}^{\mathbf{t}}$ and $\mathbf{S}^{\mathrm{c}}$ are the compliance matrices for tensile and compressive properties respectively.

\section{Results and discussion}

\subsection{Density, crystallinity and true draw ratio}

The density and $\lambda_{\mathrm{A}}$ value measured for the die-drawn material are presented in Table 1, together with the values for the undrawn compression moulded sheet. The density is unchanged for nominal draw ratios $\lambda_{\mathrm{N}}$ of 2 and 4, but reduces by approx. $10 \%$ for the highest draw ratio of $\lambda_{\mathrm{N}}=6.7$. We also observed an increase in "stress whitening" of the die-drawn sample between $\lambda_{N}=4$ and $\lambda_{N}=6.7$, as is evident in Fig. 5 .

Melt enthalpy measurements were made using DSC. A major melting peak was observed at $165.9^{\circ} \mathrm{C}$, corresponding to $\alpha$-phase crystallinity, and there was little sign of any peak corresponding to $\beta$-phase. The crystallinity was therefore calculated using the heat of fusion for $\alpha$-phase of $207.1 \mathrm{~J} / \mathrm{g}$. The crystallinities thus obtained are listed in Table 1 . Crystallinity increases systematically with draw ratio, consistent with previous work [40]. This finding, when coupled with the loss of density at the highest draw ratio, suggests voiding at the highest draw ratio. 
During the die-drawing process, the compressive stress-field being applied to the polymer within the die-section plays a significant role in preventing the creation or elongation of microvoids [7], leading to the constant density measured up to $\lambda_{\mathrm{N}}=4$. However, for the highest nominal draw ratio of $\lambda_{\mathrm{N}}=6.7$, a large amount of free-drawing occurs beyond the die-exit, to produce the final true draw ratio of $\lambda_{\mathrm{A}}=15.9$. The lack of compressive stress in free-drawing leads to voiding, as evident from the stress whitening and reduction in density for $\lambda_{N}=6.7$.

\begin{tabular}{|l|l|l|l|}
\hline $\begin{array}{l}\text { Nominal draw ratio, } \\
\lambda_{\mathrm{N}}\end{array}$ & True draw ratio, $\lambda_{\mathrm{A}}$ & Density, $\rho\left(\mathrm{g} / \mathrm{cm}^{3}\right)$ & Crystallinity \% \\
\hline 1.0 & 1.0 & $(0.909 \pm 0.002)$ & 45.6 \\
\hline 2.0 & 2.8 & $(0.910 \pm 0.002)$ & 51.7 \\
\hline 4.0 & 6.5 & $(0.909 \pm 0.001)$ & 55.0 \\
\hline 6.7 & 15.9 & $(0.822 \pm 0.002)$ & 65.0 \\
\hline
\end{tabular}

Table 1 . Density values of isotropic $\left(\lambda_{N}=1\right)$ and oriented polypropylene.

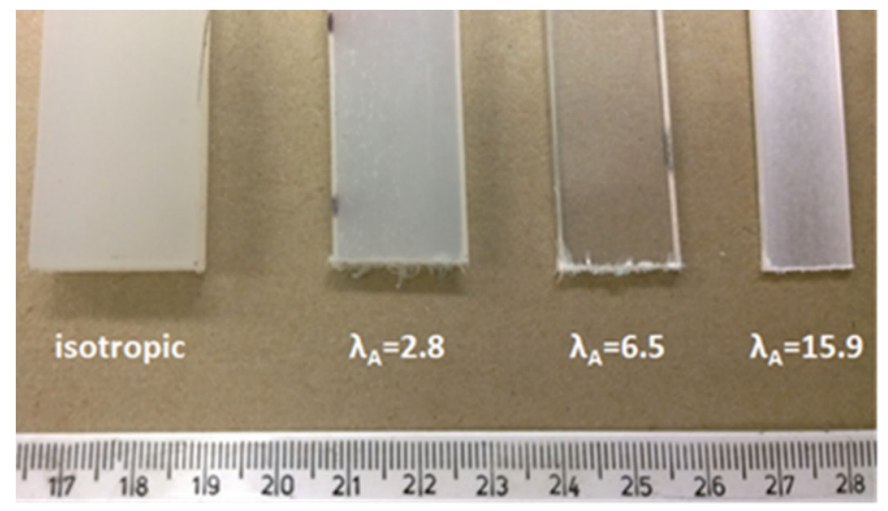

Fig. 5. Change of opacity with increasing true draw ratio $\lambda_{\mathrm{A}}$.

\subsection{Elastic properties}

The tensile tests are readily interpreted and the tensile properties are listed in Table 2 . With increasing draw ratio, there is a large increase in tensile and compressive modulus, and simultaneously a large increase in yield and fracture stress. This large property enhancement on solid-phase processing of polymer has been known for some time [12]. 
The compression moduli derived from compression testing on die-drawn cylinders correspond to different draw ratios and are plotted together with the other measured moduli in Fig. 8. This shows the consistently lower values in compression for all draw ratios.

The bend tests on the same material provide data for compressive modulus. These tests show linear elastic behaviour, but if interpreted in the conventional way they provide modulus values that are much lower than the tensile values. We analyse the tests on the assumption that compressive moduli can differ from the tensile moduli.

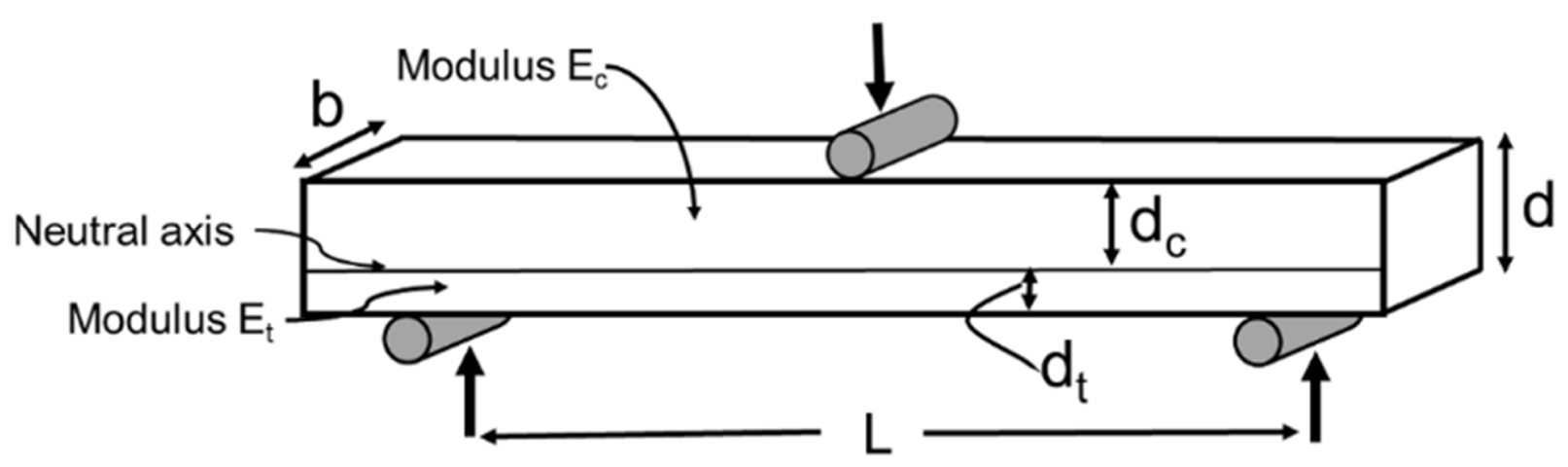

Fig. 6. Bend test on material with differing tensile and compressive moduli.

An analysis of three-point bend where the material has moduli that differ for tensile and compressive stress has been given by Chamis [41] in the framework of elementary bending theory. In this case the neutral axis of bending does not pass through the centroid of the section, as it would for a constant modulus. For a rectangular section, the distances of the neutral axis from the tensile and compressive surfaces, $d_{\mathrm{t}}$ and $d_{\mathrm{c}}$ (see Fig. 6) are related to the moduli $E_{\mathrm{c}}$ in compression and $E_{\mathrm{t}}$ in tension by:

$$
\frac{d_{t}}{d_{c}}=\left(\frac{E_{c}}{E_{t}}\right)^{\frac{1}{2}} .
$$

The analogue of the section modulus " $E I$ " in conventional bending theory is $D$, given by:

$$
D=\frac{b}{3}\left(E_{c} d_{c}^{3}+E_{t} d_{t}^{3}\right)
$$

where $b$ is the specimen's width. The central force $F$ and central deflection $\delta$ are related to the moduli via:

$$
\frac{F}{\delta}=\frac{16 b\left(E_{c} d_{c}^{3}+E_{t} d_{t}^{3}\right)}{L^{3}}
$$


Given that $E_{\mathrm{t}}$ is known from the tensile experiments, equations (18) and (20) give sufficient information to derive $E_{\mathrm{c}}$ from the observed gradients $F / \delta$ in the bend experiments. The values derived from this essentially one-dimensional analysis provide a guide to the values required for the input into three-dimensional, orthotropic analyses of the bend test that provide results taking account of finite dimensions and anisotropic effects. These were carried out using quarter models in ABAQUS [37] for each geometry used using trial-anderror to finalise the value of compressive modulus. In this procedure the modulus $E_{\mathrm{t}}$ is maintained at its measured static value and other elastic constants derived using the methods described Section 4.3. The use of finite element simulation ensures that the values obtained are not influenced by deviations from slenderness, as would be the case when using beam theory. Also, the sensitivity of the calculations to the values of the shear compliance $\mathrm{S}_{44}$, estimated using the ratio of the ultrasonically measured shear compliances, has been explored by halving its value and re-running the bend simulations at each draw ratio. This had the effect of increasing the specimen stiffnesses (force/deflection) by respectively 3.8\%, $1.7 \%$ and $2.1 \%$ for the draw ratios $2.8,6.5$ and 15.9. This suggests an insignificant effect upon the calculation of $E_{c}$. An example of a bending simulation for the draw ratio 15.9 is shown in Fig. 7. The compressive moduli of the die-drawn samples derived in this way are included in Table 2, together with the bend modulus measurement for isotropic strip at draw ratio 1 .

\begin{tabular}{|l|l|l|l|l|l|}
\hline $\begin{array}{l}\text { True draw } \\
\text { ratio } \lambda_{\mathrm{A}}\end{array}$ & $\begin{array}{l}\text { Tensile } \\
\text { modulus, } \\
\mathrm{E}_{\mathrm{t}}(\mathrm{GPa})\end{array}$ & $\begin{array}{l}\text { Compressive } \\
\text { modulus (bend } \\
\text { tests), } \mathrm{E}_{\mathrm{c}}(\mathrm{GPa})\end{array}$ & $\begin{array}{l}\text { True tensile } \\
\text { yield stress } \\
(\mathrm{MPa})\end{array}$ & $\begin{array}{l}\text { True } \\
\text { fracture } \\
\text { stress (MPa) }\end{array}$ & $\begin{array}{l}\text { Strain at } \\
\text { break (\%) }\end{array}$ \\
\hline 1 & $(1.8 \pm 0.1)$ & $1.8 \pm 0.1$ & $(39 \pm 2)$ & $(46 \pm 3)$ & $(60 \pm 20)$ \\
\hline 2.8 & $(4.9 \pm 0.8)$ & $1.8 \pm 0.2$ & $(62 \pm 4)$ & $(160 \pm 10)$ & $(53 \pm 5)$ \\
\hline 6.5 & $(10 \pm 1)$ & $2.9 \pm 0.5$ & $(64 \pm 4)$ & $(230 \pm 30)$ & $(6 \pm 3)$ \\
\hline 15.9 & $(23 \pm 1)$ & $3.85 \pm 0.5$ & $(74 \pm 4)$ & $(300 \pm 40)$ & $(3 \pm 1)$ \\
\hline
\end{tabular}

Table 2. Results from mechanical testing of the die-drawn strip and undrawn material.

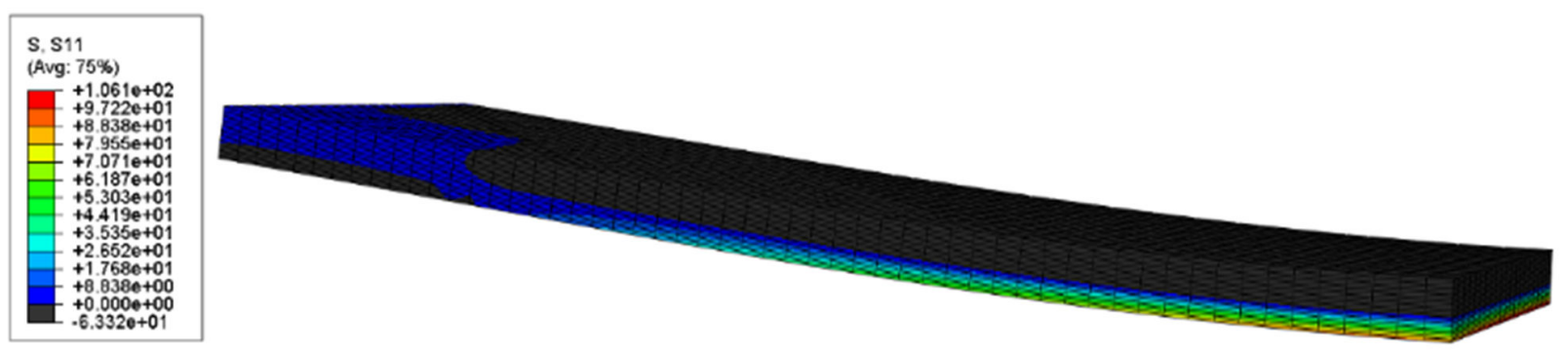


Fig. 7. Quarter model of bend specimen with the centre of the section at the right and central axial plane at the front. The front vertical face is a symmetry boundary. Contours of axial stress are shown with negative values black, showing neutral surface in the bottom half of beam. Elastic properties are for draw ratio 15.9.

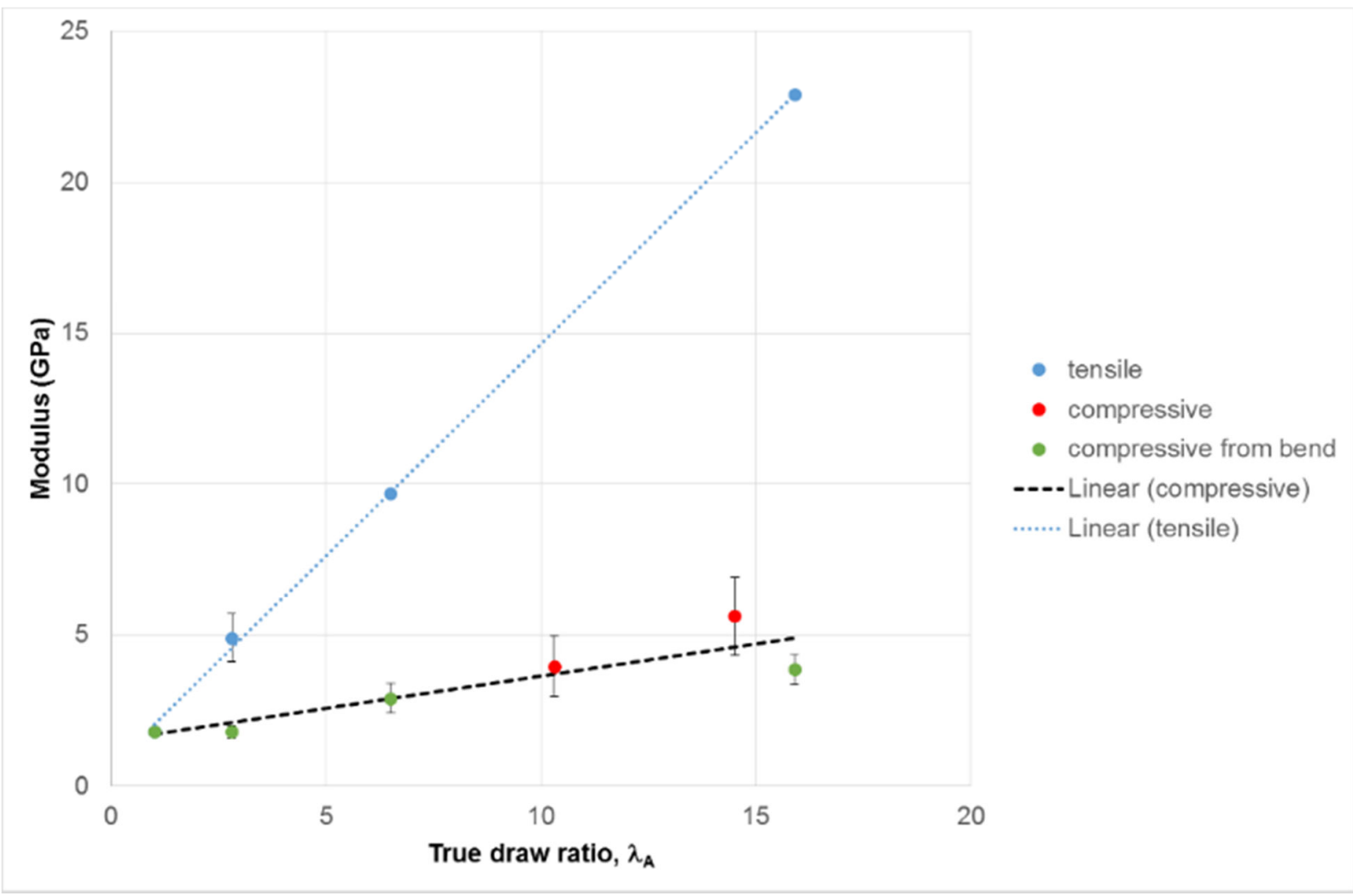

Fig. 8. Modulus along the drawing axis in tension and compression.

\subsection{Model parameterisation}

The Finite Element simulations used an orthotropic elastic material model which distinguishes between states of tension and compression in the material draw (3) direction. The model is parameterised by specifying the elements $C_{i j}$ of the stiffness matrix $\mathbf{C}$ in equation (11) using the above experimental measurements and published ultrasonic data.

Leung and Choy [42] have published full sets of stiffness constants $C_{\mathrm{ij}}$, determined by an ultrasonic method, for uniaxially oriented polypropylene at room temperature and for a range of draw ratios between 1 and 20. Their values are summarised in Fig. 9. Stiffnesses measured ultrasonically cannot in general be equated with static values, as the rates of strain are much higher for ultrasonic testing and polymers are viscoelastic and therefore strainrate dependent. The room temperature data of Leung and Choy do, however, show that $C_{11}$ 
does not vary strongly with extension ratio, and so we assume that for our PP the value of $E_{1}$ at all draw ratios is equal to that measured in static conditions for the undrawn material. It was also assumed that the Poisson's ratios $v_{21}$ and $v_{31}$, as derived from the ultrasonic stiffness by inversion of $\mathbf{C}$ to give an ultrasonic compliance matrix $\mathbf{S}$, and subsequent use of equation (8), also apply for static conditions. Then, static values for the components of the left upper $3 \times 3$ part of the matrix in equation (6) are derived using equations (7) and (8). At this point the values used for modulus $E_{1}$ and $E_{3}$ are the static values of Table 2, with $E_{3}=E_{t}$ for tensile conditions and $E_{3}=E_{c}$ for compressive conditions (the precise definitions of tensile and compressive conditions are given in section 3.3). The remaining compliance terms are $s_{66}$ and $s_{44 .} S_{66}$ is defined by equation (10). Finally, the value of $s_{44}$ is established by assuming that the ratio $s_{44} / s_{66}$ is equal to the ratio of the ultrasonic values.

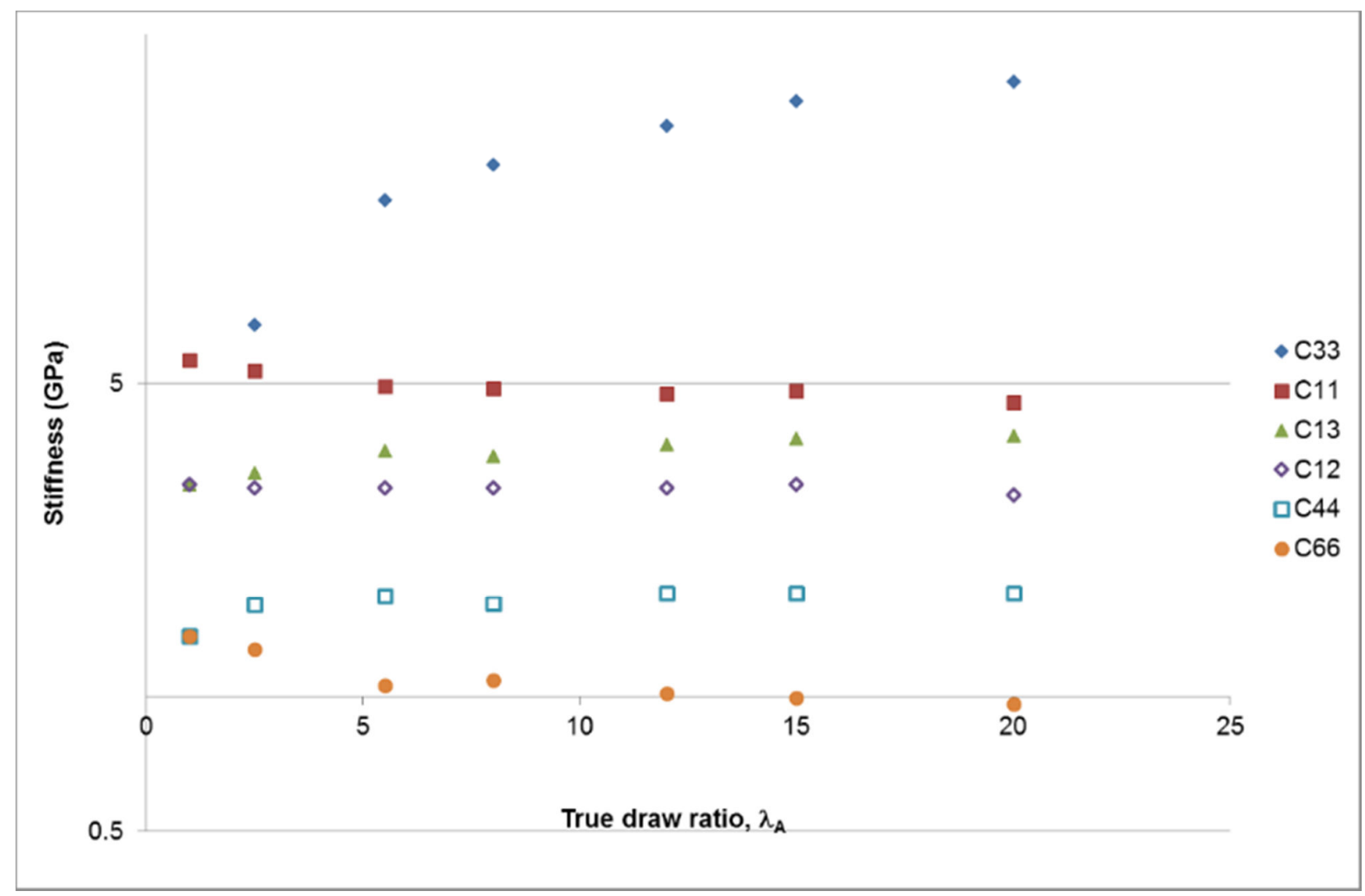

Fig. 9. Ultrasonic stiffness values from Leung and Choy [42].

For each of the experimental draw ratios $\lambda_{\mathrm{A}}$ of $2.8,6.5$ and 15.9, a set of compliances is interpolated from the data of Fig. . Then, the procedures outlined in the paragraph above are applied to generate compliance matrices for static conditions. At each draw ratio, two compliance matrices are derived, one for $s_{33}=1 / E_{\mathrm{t}}$ and one for $s_{33}=1 / E_{\mathrm{c}}$. The compliance constants are summarised in Table 3. 


\begin{tabular}{|c|c|c|c|c|c|c|}
\hline \multicolumn{7}{|c|}{ Isotropic } \\
\hline & \multicolumn{2}{|c|}{$S_{11}=s_{22}=s_{33}$} & \multicolumn{2}{|c|}{$\mathrm{S}_{12}=\mathrm{S}_{13}=\mathrm{S}_{23}$} & \multicolumn{2}{|c|}{$\mathrm{S}_{44}=\mathrm{S}_{55}=\mathrm{S}_{66}$} \\
\hline & \multicolumn{2}{|l|}{0.556} & \multicolumn{2}{|l|}{-0.192} & \multicolumn{2}{|l|}{1.496} \\
\hline \multicolumn{7}{|c|}{ Tensile $\mathbf{S}^{\mathbf{t}}$} \\
\hline $\begin{array}{l}\text { Draw } \\
\text { ratio }\end{array}$ & $\mathbf{S}_{11}^{\mathrm{t}}=\mathbf{S}_{22}^{\mathrm{t}}$ & $\mathbf{S}_{12}^{\mathrm{t}}$ & $\mathbf{S}_{23}^{\mathrm{t}}=\mathbf{S}_{13}^{\mathrm{t}}$ & $\mathbf{S}_{33}^{\mathrm{t}}$ & $S_{44}^{t}=S_{55}^{t}$ & $\mathbf{s}_{66}^{t}$ \\
\hline 2.8 & 0.556 & -0.219 & -0.146 & 0.204 & 1.142 & 1.549 \\
\hline 6.5 & 0.556 & -0.298 & -0.055 & 0.103 & 1.021 & 1.707 \\
\hline 15.9 & 0.556 & -0.310 & -0.043 & 0.044 & 0.924 & 1.731 \\
\hline \multicolumn{7}{|c|}{ Compressive $\mathbf{S}^{\mathbf{c}}$} \\
\hline $\begin{array}{l}\text { Draw } \\
\text { ratio }\end{array}$ & $\mathrm{S}_{11}^{\mathrm{c}}=\mathrm{S}_{22}^{\mathrm{c}}$ & $\mathrm{S}_{12}^{\mathrm{c}}$ & $\mathrm{s}_{23}^{\mathrm{c}}=\mathrm{S}_{13}^{\mathrm{c}}$ & $\mathrm{s}_{33}^{\mathrm{c}}$ & $\mathrm{S}_{44}^{\mathrm{c}}=\mathrm{S}_{55}^{\mathrm{c}}$ & $\mathrm{s}_{66}^{\mathrm{c}}$ \\
\hline 2.8 & 0.556 & -0.219 & -0.146 & 0.556 & 1.142 & 1.549 \\
\hline 6.5 & 0.556 & -0.298 & -0.556 & 0.263 & 1.021 & 1.707 \\
\hline 15.9 & 0.556 & -0.310 & -0.043 & 0.120 & 0.924 & 1.731 \\
\hline
\end{tabular}

Table 3. Compliance constants, $\boldsymbol{S}\left(\mathrm{GPa}^{-1}\right)$.

\subsection{Nanoindentation experiments}

Experimental results for the indentation modulus against indentation depth $h_{\mathrm{c}}$ measured both in the axial and transverse directions, $M_{3}, M_{1}$ and $M_{2}$ respectively. The tests from the 
two transverse directions gave indistinguishable modulus values. The reason for conducting them was to validate our choice of a transverse isotropic model in order to describe our oriented materials, and calculate their elastic parameters, which we used in Finite Element Analysis modelling. Hence, only a comparison between results from $\mathrm{M}_{3}$ and $\mathrm{M}_{1}$ direction are shown in Fig. 10.

In all cases, an increase in $\mathrm{M}$ with decreasing $h_{\mathrm{c}}$ was observed, which is indicative of viscoelastic polymers when tested using a Berkovitch indenter. This has been investigated thoroughly by Alisafaei and Han [43] as well as Han et al. [44] and it is out of this paper's scope. Similarly, Beake and Leggett [20] have also reported similar behaviour in uniaxially and biaxially oriented PET films.

A clear and significant increase in the axial indentation modulus $M_{3}$ is observed with increasing draw ratio. This is in line with the increase in larger-scale moduli measured along the drawing axis (see Fig. 8). The indentation modulus in the transverse direction $M_{1}$ shows a much lower dependence on the draw ratio away from the isotropic value. 


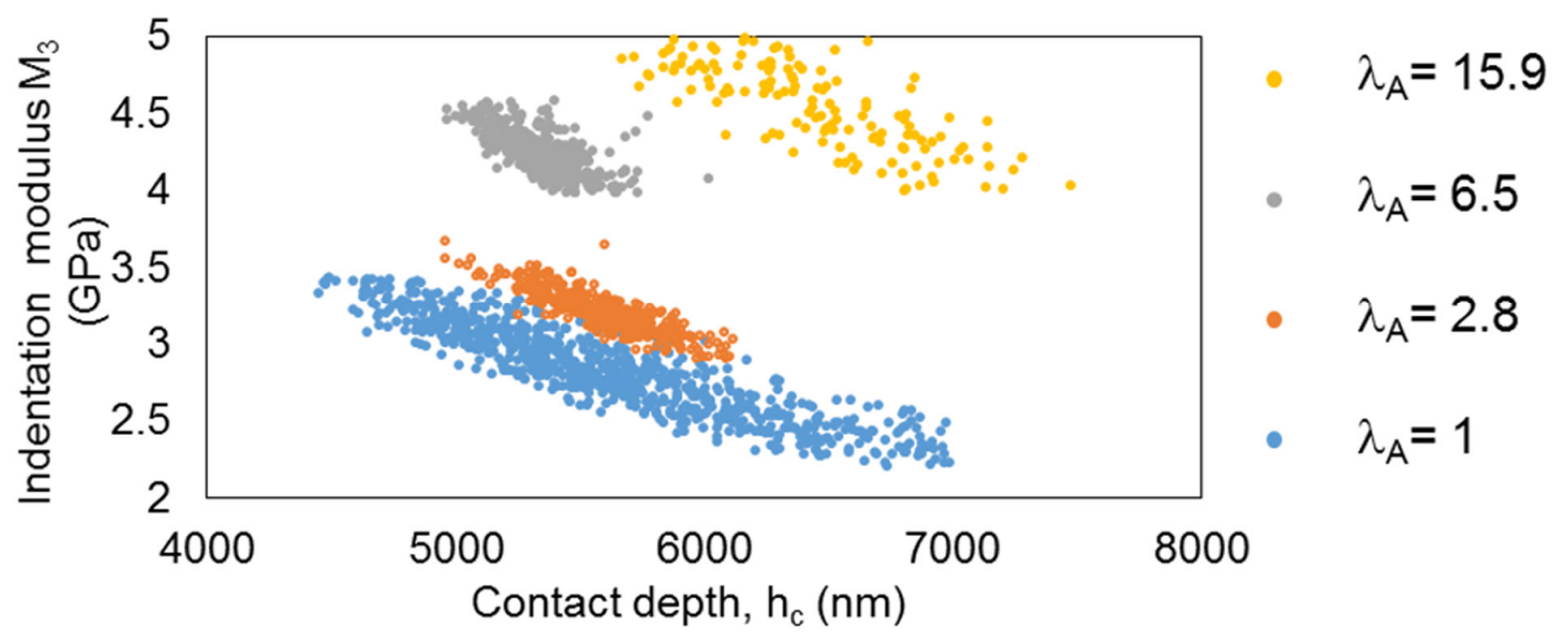

(a)

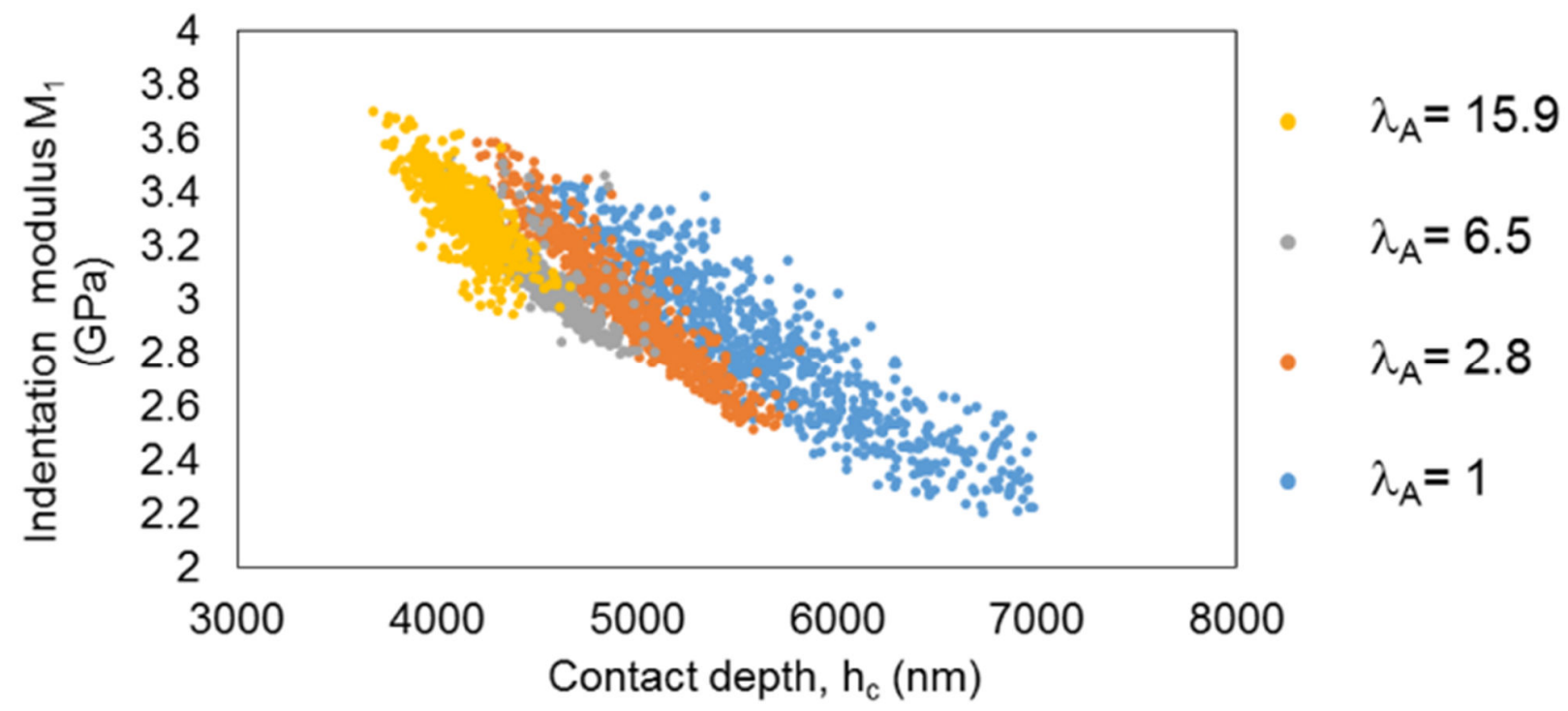

(b)

Fig. 10. Indentation modulus as a function of contact depth for nanoindentation tests performed (a) axially along the draw direction and (b) transverse to it, for the different draw ratios $\lambda_{\mathrm{A}}$. 


\subsection{Nanoidentation modelling}

\subsubsection{Isotropic material}

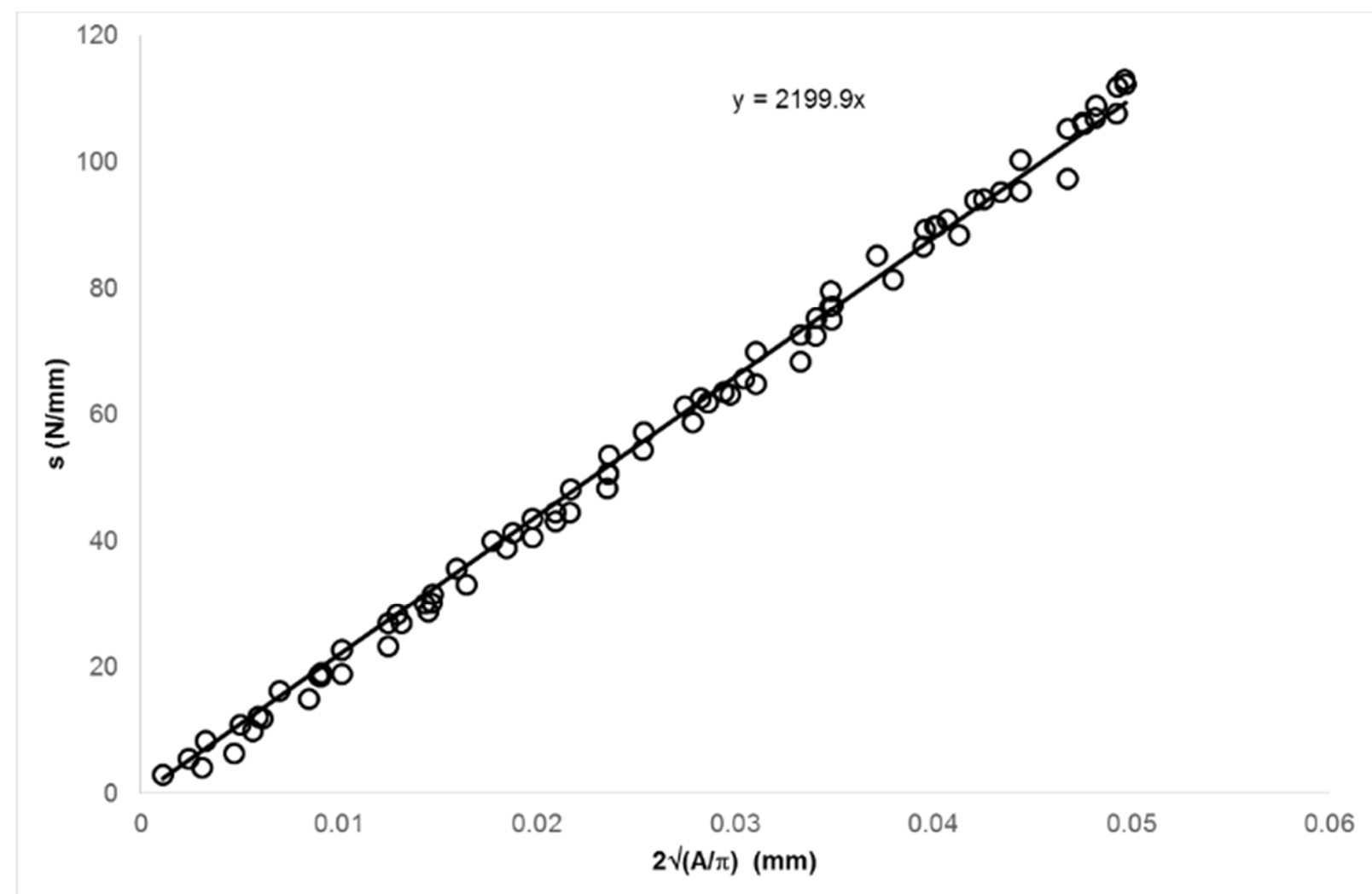

Fig. 11. Plot of stiffness according to equation (4) to give a gradient equal to the indentation modulus $M$.

According to equation (4), a plot of $s$ against $2 \sqrt{ }(A / \pi)$ should be linear with gradient $M$. This method is used to derive $M$ values from the finite element results. Fig. 11 shows the plot for the indentation model of a Berkovich indenter into isotropic material (for the finite element model shown in Fig. 3). The material corresponds to an undrawn polymer with modulus 1.8 GPa and Poisson's ratio 0.346 , corresponding to the compliance values for isotropic material given in Table 3. The $M$ value of $2.20 \mathrm{GPa}$ from the indentation analysis compares with that calculated for $E_{\mathrm{r}}$ in equation (13) of $2.04 \mathrm{GPa}$. Sakharova et al. [35] have noticed a similar discrepancy between finite element results and input parameters, and have introduced a factor $\beta$ equivalent to

$$
\beta=\frac{M}{E_{\mathrm{r}}} .
$$


For our analysis, we obtain the value $\beta=1.076$. This is to be compared with that of Sakharova et al. of 1.074 for finite element analysis of Berkovich indentation of isotropic material. The same authors have produced a value $\beta=1.029$ for simulations with a conical indenter of semi-angle $70.3^{\circ}$. We have used a conical indenter with the same angle in an analysis that is otherwise identical to the model of Fig. 3, to give a value $\beta=1.036$. Dao et al. [33] have derived values of $\beta$ of 1.096 and 1.06 for Berkovich and conical indenters respectively. $\beta$ increases as the indenter shape deviates more from the cone; intermediate values are reported for the four-faced Vickers indenter $[35,36]$. The large $\beta$ value for the Berkovich indenter reflects a genuine physical effect of the difference between its geometry and that of a conical indenter. The smaller $\beta$ values for the conical indenter arise, according to Hay et al. [45], from inaccuracy in the analysis of the cone indentation of Sneddon [46] that lies behind the assumed relation $M=E_{\mathrm{r}}$ (see equations (4) and (13)). Hay et al. [45] found that the lateral displacements at the surface of the indentation do not exactly coincide with the surface of a cone except for incompressible material with Poisson's ratio value of $1 / 2$. They have derived $\beta$ values that depend on Poisson's ratio, such that for Poisson's ratio $0.35, \beta \approx 1.04$ for a cone semi-angle $70.3^{\circ}$. Our finite element mesh and analysis procedures are consistent with the established findings for isotropic material.

\subsubsection{Orthotropic material}

For our analyses of orthotropic material, we seek verification from equations (14) and (15) of Delafargue and Ulm [39]. Their linear elastic analysis is based on material with identical responses in tension and compression, and to make the comparison, we use the tensile elastic properties of Table 3. The analytical and finite element derived indentation moduli are compared in Table 4 . Values of $\beta\left(M_{1} / M_{1}^{a}\right.$ and $\left.M_{3} / M_{3}^{a}\right)$ are greater than unity except for $M_{1} / M_{1}^{a}$ at the draw ratios 6.5 and 15.9 when they are very close to it. Overall, $0.996<\beta<$ 1.024 , a similar level for the isotropic case. The results signify that the finite element meshes and associated analysis are fit for purpose for orthotropic polymer indentation.

\begin{tabular}{|l|l|l|l|l|}
\hline Draw ratio, $\lambda_{\mathrm{A}}$ & $M_{1}^{\mathrm{a}}(\mathrm{GPa})$ & $M_{1}(\mathrm{FE})(\mathrm{GPa})$ & $M_{3}^{\mathrm{a}}(\mathrm{GPa})$ & $M_{3}(\mathrm{FE})(\mathrm{GPa})$ \\
\hline 2.8 & 2.38 & 2.42 & 4.32 & 4.35 \\
\hline 6.5 & 2.33 & 2.32 & 5.74 & 5.79 \\
\hline 15.9 & 2.48 & 2.47 & 9.76 & 9.99 \\
\hline
\end{tabular}

Table 4. Analytical and finite element-derived indentation moduli for a conical indenter. 


\subsubsection{Orthotropic material with tensile-compressive asymmetry}

We now proceed to apply this method Berkovich indentation of oriented polymer, using a stress-strain law that recognises the asymmetry in elastic modulus when loading in tension or compression along the draw direction (section 3.3). The model predictions are derived using the finite element models of Fig. 3, with input data given in Table 4. The predicted indentation modus for the same draw ratios as tested are presented in Fig. 12 and discussed in section 4.6.

\subsection{Comparison of model with experiment}

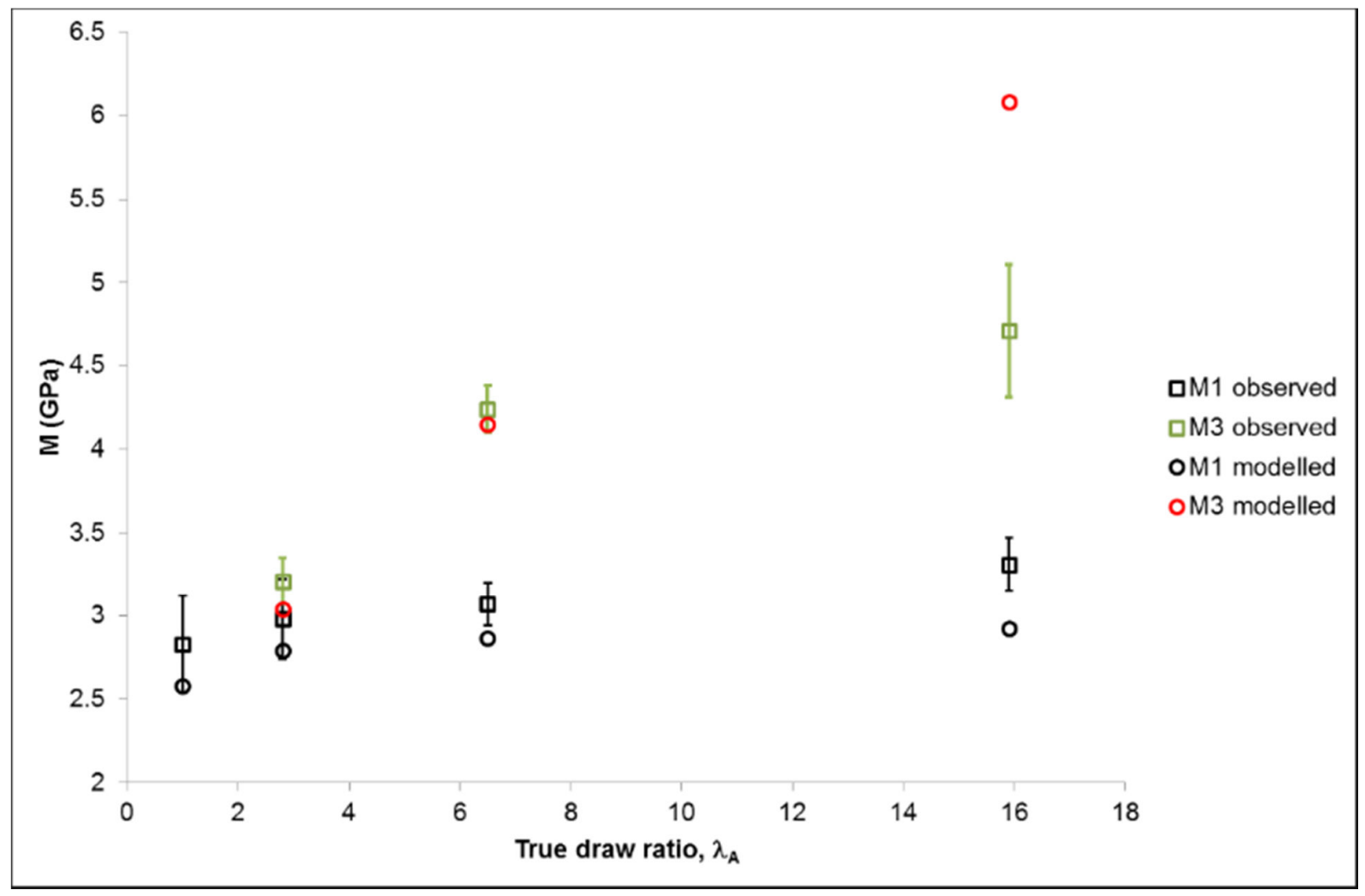

Fig. 12. Comparison of observed and predicted indentation moduli as a function of axial draw ratio.

The measured indentation moduli for nanoindentation along the axial $M_{3}$ and transverse $M_{1}$ directions are compared with the finite element model predictions in Fig. 12. In most cases the prediction is within the experimental error bars. The greatest discrepancy is the axial indentation modulus $M_{3}$ at the highest draw ratio. As noted in section 4.1 above, this is the only draw ratio for which voiding is observed, via visible stress-whitening and density measurement. We would expect indentation into voids to give low modulus values, 
and also more experimental variation as the polymer is inhomogeneous at a scale detectable from nanoindentation.

On comparing the values in Fig. 12 with those obtained using only tensile properties in Table 4, it becomes clear that the latter values for $M_{3}$ are very much higher than both the experimental observations and the finite element predictions using the method developed here; the inclusion of both compressive and tensile Young's moduli decreases the calculated value of $M_{3}$ from $\sim 10 \mathrm{GPa}$ to $\sim 6 \mathrm{GPa}$ at draw ratio 15.9, and from $5.7 \mathrm{GPa}$ to 4.2 for draw ratio 6.5. The effects on $M_{1}$ are also significant.

For the transverse tests and simulations that give the values of $M_{1}$, the indented material plane is anisotropic, and so it was expected that the orientation of the Berkovich indenter with respect to the principal axes of orthotropy would have some influence on the results. This effect has been explored with the simulations, by rotating the indenter about its central axis by 15 and $30^{\circ}$. The latter rotation puts one of the sides of the indenter's triangular section normal to the stiff material 3 axis, as opposed to being parallel to it as in the unrotated $\left(0^{\circ}\right)$ test shown in Fig. 2(b). The $0^{\circ}$ and $30^{\circ}$ models thus represent the extreme orientations of the indenter. Simulations at a range of rotation angles have shown that the $0^{\circ}$ orientation gives the maximum $M_{1}$ and the $30^{\circ}$ gives the minimum, and that they differ in the range $1.1-1.6 \%$. This suggests that the indenter orientation has no significant effect experimentally.

\section{Conclusions}

When measuring elastic behaviour, the interpretation of nanoindentation tests for elastically anisotropic material is more complex than for isotropic material, as the 'reduced modulus' of isotropic elasticity must be generalised. The more general parameter, the indentation modulus, is a function of nine elastic constants for a generally orthotropic material. In the case of uniaxially oriented polymer, which is transversely isotropic, it depends on six independent elastic constants. In the present work on die-drawn polypropylene, the constants were evaluated for three draw ratios using a combination of static and ultrasonic mechanical data.

A further complication was that the static testing showed that the elastic moduli were different in tension from in compression. Values of Young's modulus obtained in compression were lower than those obtained in tension, by a factor of $\sim 5$ at the highest draw ratio of 16 .

From these considerations it follows that, to interpret nanoindentation in oriented polymer, a material model is required that combines orthotropic elasticity with tensioncompression asymmetry. Three-dimensional finite element analyses of nanoindentation were conducted that incorporated such a model as a user-defined subroutine. Using the elastic constants derived from static and ultrasonic tests as input data, predictions of nanoindention modulus were obtained for indentation in directions both along and normal to the direction of orientation. The predictions obtained were at a good level of accuracy except at the highest orientations when the material is voided material. They confirmed the 
observation of higher values of indentation modulus along the axis of orientation as opposed to normal to it.

\section{Acknowledgements}

This work was supported by Sinopec (China Petrochemical Technology Company, Beijing, China).

\section{References}

[1] Coates P.D., Ward I.M., Drawing of Polymers through a Conical Die, Polymer, 20, (1979) 1553-1560.

[2] Coates P.D., Ward I.M., Die Drawing - Solid-Phase Drawing of Polymers through a Converging Die, Polymer Engineering and Science, 21, (1981), 612-618.

[3] Richardson A., Parsons B., Ward I.M., Production and properties of high stiffness polymer rod, sheet and thick filament oriented by large-scale die-drawing, Plast. Rubb. Proc. Appl. 6 (1986), 347-361.

[4] Taraiya A.K., Ward I.M., The production and properties of die-drawn biaxially oriented polypropylene tube, Plast. Rubb. Proc. Appl. 15 (1991) 5-11.

[5] Selwood A., Ward I.M. and Parsons B., The production of oriented polymer tube by the die-drawing process. Plast. Rubb. Proc. Appl. 8 (1987) 49-58.

[6] Morath C.C., Taraaiya A.K., Richardson A., Craggs G., Ward I.M., The development of continuous large-scale die-drawing for the production of oriented polymer rods and tubes, Plast. Rubb. Proc. Appl. 19 (1993) 55-62.

[7] Motashar F.A., Unwin A.P., Craggs G., Ward I.M., Analytical and experimental study of the die drawing of circular rods through through conical dies, Polymer Engineering and Science 33 (1993) 1288-1298.

[8] Ward I.M., A review of recent developments in the processing and properties of oriented polyethylene, Plast. Rubb. Proc. Appl, 19 (1993) 7-13.

[9] Selwood A., Parsons B., Ward I.M., The production and properties of die-drawn polyethylene pipe, Plast. Rubb. Proc. Appl. 11 (1989)229-233.

[10] Taraiya A.K., Ward I.M., Production and properties of die-drawn biaxially oriented polyethylene tubes, Journal of Applied Polymer Science 59 (1996)627-638.

[11] Hansard S.A., Atkinson J.R., Ward I.M., High strength oriented MDPE pipes, Plast. Rubb. Proc. Appl. 22 (1994) 1-8.

[12] Ward I.M., Taraiya A.K., Coates P.D., Solid state extrusion and die drawing, in: Ward I.M., Coates P.D., Dumoulin M.M. (Eds.), Solid phase processing of polymers, Hanser, Munich, 2000, pp. 328-367. 
[13] Mohanraj J., Bonner M.J., Barton D.C., Ward I.M., Physical and mechanical characterization of oriented polyoxymethylene produced by die-drawing and hydrostatic extrusion, Polymer 47 (2006) 5897-5908.

[14] Brisco B.J., Fiori L., Pelillo E., Nano-indentation of polymeric surfaces J. Phys. D: Appl. Phys. 31 (1998) 2395-2405.

[15] Jee A-Y., Lee M., Comparative analysis on the nanoindentation of polymers using atomic force microscopy Polymer Testing 29 (2010) 95-99.

[16] Gibson R.F., A review of recent research on nanoindentation of polymer composites and their constituents, Composites Science and Technology 105, (2014) 51-65.

[17] Chen J., Bell G.A., Dong H., Smith J.F., Beake B.D., A study of low temperature mechanical properties and creep behaviour of polypropylene using a new sub-ambient temperature nanoindentation test platform, Journal of Physics D - Applied Physics, 43, (2010) 425404.

[18] Lesan-Khosh R., Bagheri R., Asgari S., Nanoindentation of Isotactic Polypropylene: Correlations Between Hardness, Yield Stress, and Modulus on the Local and Global Scales, Journal of Applied Polymer Science, 121 (2011) 930-938.

[19] Zia Q., Tranchida D., Androsch R., Schroner H., Effect of crystal habit and superstructure on modulus of elasticity of isotactic polypropylene by AFM nanoindentation, J Mater Sci 47 (2012) 3040-3045.

[20] Beake B.D., Leggett G.J., Nanoindentation and nanoscratch testing of uniaxially and biaxially drawn poly(ethylene terephthalate) film, Polymer 43, (2002) 319-327.

[21] Fasce L.A., Costamanga V., Pettarin V., Strumia A., Frontini P.M., Poly(acrylic acid) surface grafted polypropylene films: Near surface and bulk mechanical response. Express polymer letters 2 (2008) 779-790.

[22] Norambuena-Contreras J., Gonzalez-Torre I., Vivanco J.F., Gacitúa W., Nanomechanical properties of polymeric fibres used in geosynthetics, Polymer Testing 54(2016) 67-77.

[23] Senden D.J.A., Peters G.W.M., Govaert .LE., Van Dommelen J.A.W., Anisotropic yielding of injection molded polyethylene: Experiments and modeling, Polymer 54 (2013) 58995908.

[24] Duckett R.A., Ward I.M., Zihlif A.M., Direct measurements of the reverse stress asymmetry in the yielding of anisotropic polypropylene, J Mater Sci Lett. 7 (1972) 480-482.

[25] Carnelli D., Lucchini R., Ponzoni M., Contro R., Vena P., Nanoindentation testing and finite element simulations of cortical bone allowing for anisotropic elastic and inelastic mechanical response, Journal of Biomechanics, 7 (2011) 1852-1858.

[26] Reisinger A.G., Pahr D.H., Zysset P.K., Elastic anisotropy of bone lamellae as a function of fibril orientation pattern, Biomechanics and Modeling in Mechanobiology 10, (2011) 67-77. 
[27] Casanova M., Balmelli A., Carnelli D., Courty D., Schneider P., Müller R., Nanoindentation analysis of the micromechanical anisotropy in mouse cortical bone. Royal Society Open Science, 4 (2017) 2.

[28] Qasmi M., Delobelle P., Influence of the average roughness $\mathrm{R}_{\mathrm{ms}}$ on the precision of the Young's modulus and hardness determination using nanoindentation technique with a Berkovich indenter, Surface and Coatings Technology 201 (2006) 1191-1199.

[29] Chen Z., Diebels S., Modelling and parameter re-identification of nanoindentation of soft polymers taking into account effects of surface roughness, Computers and Mathematics with Applications 64 (2012) 2775-2786.

[30] Oliver W.C., Pharr G.M., An improved technique for determining hardness and elastic modulus using load and displacement sensing indentation experiments, J. Mater. Res. 7 (1992) 1564-83.

[31] Bhattacharya A.K., Nix W.D., Finite element simulation of indentation experiments, International, Journal of Solids and Structures 24(1988) 881-891.

[32] Lichinchi M., Lenardi C., Haupt J., Vitali R., Simulation of Berkovich naniindentation experiments on thin films using finite element method, Thin Solid Films 312 (1998) 240248.

[33] Dao M., Chollacoop N., Van Vliet K.J., Venkatesh T.A., Suresh S., Computational modelling of the forward and reverse problems in instrumented sharp indentation, Acta Materialia 49 (2001) 3899-3918.

[34] Huang X., Pelegri A.A., Finite element analysis on nanoindentation with friction contact at the film/substrate interface. Composites Science and Technology 67 (2007) 1311-1319.

[35] Sakharova N.A., Fernandes J.V., Antunes J.M., Oliveira M.C., Comparison between Berkovich, Vickers and conical indentation tests: A three-dimensional simulation study, International Journal of Solids and Structures 46 (2009) 1095-1104.

[36] Antunes J.M., Menezes L.F., Fernandes, J.V., Three-dimensional numerical simulation of Vickers indentation tests, International Journal of Solids and Structures 43, (2006) 784806.

[37] ABAQUS v 6.14 Dassault Systemes 2016.

[38] Ward I.M., Sweeney J., Mechanical Properties of Solid Polymers third ed., Wiley, Chichester, 2013.

[39] Delafargue A., Ulm F-J., Explicit approximations of the indentation modulus of elastically orthotropic solids for conical indenters, International Journal of Solids and Structures 41 (2004) 7351-7360.

[40] Chaffey E.C., Taraiya A.K., Ward I.M., Orientation of polypropylene sheets produced by die-drawing and rolling. Polymer Engineering and Science 37 (1997) 1774-1784. 
[41] Chamis C.C., Analysis of the three-point bend test for materials with unequal tension and compression properties, NASA TN D-7572, Washington DC, 1974

[42] Leung W.P., Choy C.L. The elastic constants of ultradrawn polyethylene Journal of Polymer Science: Polymer Physics edition 21 (1983) 725-752.

[43] Alisafei F., Han C.S., Indentation depth dependent mechanical behaviour in polymers, Advances in Condensed Matter Physics, 2015 (2015) 391579.

[44] Han C.S., Sanei S.H.R., Alisafaei F., On the origin of indentation size effects and depth dependent mechanical properties of elastic polymers, Journal of Polymer Engineering, 36 (2015) 103-111.

[45] Hay J.C., Bolshakov A., and G.M., A critical examination of the fundamental relations used in the analysis of nanoindentation data, Journal of Materials Research, 14 (1999), 2296-2305.

[46] Sneddon I.N., The relation between load and penetration in the axisymmetric Boussinesq problem for a punch of arbitrary profile, Int. J. Eng. Sci. 3 (1965) 47-57 